\title{
V CONGRESO DEL PSUC
}

Desde el día 2 hasta el 6 de enero de 1981 se ha celebrado en Barcelona el V Congreso del Partido de los Comunistas Catalanes.

El Congreso tenía lugar en un momento especialmente conflictivo en el PSUC, ya que existía la conciencia generalizada de la necesidad de un cambio de rumbo en la dirección del partido. A ello habían contribuido diversos factores, entre los que podemos destacar los siguientes:

- Desplazamiento del electorado catalán hacia la opción de derechas ${ }^{1}$.

- Florecimiento de los partidos de corte nacionalista, en detrimento de los de ámbito estatal ${ }^{2}$.

- Importante aumento del desencanto político ${ }^{3}$.

A los puntos anteriormente citados debemos agregar otros aspectos del propio partido, tales como:

- Pérdida de militancia ${ }^{4}$.

- Sensible pérdida cualitativa en las elecciones sindicales del sindicato más afín al PSUC: Comisiones Obreras ${ }^{5}$.

- Carencia de una alternativa política viable, ya que el PSUC, al haber sido derrotado (relativamente) a nivel electoral, no podía presentarse como la única alternativa de la izquierda. Así, debía elaborar una nueva política adecuada a las actuales circunstancias.

${ }^{1}$ En las elecciones del 20 de marzo, el PSC-PSOE perdió en relación a las anteriores el 5 por 100 de los votos, y el PSUC más de 2.000 votos.

${ }_{2}$ En las citadas elecciones, Convergencia $\mathrm{i}$ Unió tuvo un considerable aumento de votos, al igual que Esquerra Republicana, a costa de UCD y del PSC-PSOE fundamentalmente.

${ }^{3} \mathrm{El}$ abstencionismo en Cataluña ha venido incrementándose constantemente desde el 15 de junio de 1977.

4 Desde la legalidad del partido se calcula en 15.000 el número de militantes que han abandonado el mismo.

${ }^{5}$ Este sindicato ha sufrido un importante retroceso en cuanto a número de representantes sindicados se refiere, especialmnte en Lérida y Gerona, así como en la fábrica SEAT de Barcelona. 
Los puntos anteriormente expuestos habían generado en amplios sectores del partido:

- Confrontaciones internas y un aumento del grado de criterio ideológico de carácter crítico a la dirección.

- Deseos de distanciamiento del PCE.

Todo ello había desarrollado diversas tendencias dentro del partido, algunas de las cuales ya habían aflorado en el anterior Congreso de 1977. Podemos reunir las mismas en las siguientes:

- Bandera Blanca. Es considerada como la tendencia más conservadora del partido, aunque cuantitativamente muchos de sus militantes procedan de grupos marxistas-leninistas. Se caracteriza por su tendencia carrillista. Entre sus dirigentes principales figuran Solé Tura y Jorge Borja.

- Eurocomunistas Puros. Aunque no carrillista, su rechazo al secretario general del PCE le ha llevado a aliarse con el grupo leninista. Su representante más destacado es Antoni Gutiérrez Díaz (secretario general hasta el V Congreso).

- Leninista. Fue el vencedor en el anterior Congreso del PSUC. Su principal fuerza reside en CC. OO. Mantiene el enfrentamiento contra Carrillo y defiende la democratización interna del partido. Rechaza la política internacional soviética.

- Afgano. Se le puede considerar el sector histórico del partido. Aglutina a la izquierda del PSUC. Defiende la política exterior soviética. Eventualmente ha mantenido alianzas con los leninistas en contra de Bandera Blanca.

\section{DESARROLLO DEL CONGRESO}

En el inicio del Congreso se pusieron de manifiesto las tensiones derivadas de las posturas indicadas en el anterior apartado; así, la dirección del PSUC fue derrotada en su proyecto de reglamento por el Congreso, consiguiéndose por los sectores críticos que la elección del Comité Central fuese a puerta abierta.

El resultado de la votación fue: 542 votos a favor, 125 en contra y 49 abstenciones.

Posteriormente, en otras votaciones de carácter aplastante se enmendará el proyecto de reglamento en el sentido de que fuesen dados a conocer todos los resultados de la elección del nuevo Comité Central, tanto en lo que respecta al número de votos obtenidos por los elegidos como por los rechazados.

\section{Informe del Comité Central}

El secretario general, Antoni Gutiérrez Díaz, presentó el informe del Comité Central, en el que comenzó reafirmando la política eurocomunista del partido. En el mismo cabe destacar los siguientes apartados:

\section{a) Situación internacional}

Se refirió a la crisis económica internacional, sobre la que dijo: «Ha abierto un proceso que comporta una cierta pérdida de la hegemonía imperialista, y en primer 
lugar la de Estados Unidos, que ha ido perdiendo posiciones en la economía mundial, ha sufrido grandes derrotas - como la del Vietnam o la de Angola- y no ha podido detener la caída del Sha o de Somoza. Frente a esta pérdida relativa de la hegemonía no ha encontrado otras respuestas para recuperar las posiciones perdidas que desencadenar la tensión internacional... imponiendo una ofensiva ideológica y política que presenta los incrementos del precio del petróleo y de los salarios como las causas de todos los males económicos y a la Unión Soviética como la culpable de la tensión internacional» 6 .

Posteriormente se refirió a la actuación soviética en Afganistán, pero no en un tono condenatorio, sino levemente crítico y mediante la utilización de frases diluidas y matizadas, al contrario de los párrafos relativos a la política china, claramente condenatoria. «En la escena internacional, los países socialistas no han quedado al margen de la dinámica de la tensión generada por el imperialismo, ya sea fortaleciéndose indirectamente, como es el caso de China Popular, con su política de acercamiento a Estados Únidos y al Japón, ya sea agravando situaciones con aumento de tensión internacional, como el caso de la intervención militar de China en Vietnam, de Vietnam en Campuchea o de la Unión Soviética en Afganistán» ?.

Posteriormente volverá a referirse a este último país, aunque en términos diferentes: «Otros han representado auténticos cambios revolucionarios, como los de Afganistán, Yemen del Sur, Granada, etc.» ${ }^{8}$.

Cabe destacar también en este apartado del informe la crítica realizada al Gobierno español por su actuación en el caso del Sahara y por el apoyo prestado al régimen actual de Guinea Ecuatorial.

En el citado informe existe una referencia clara contra el ingreso de España en la OTAN.

\section{b) Situación española}

Criticó la política económica del Gobierno, incidiendo especialmente en el paro y la inflación, rechazando el Estatuto de los Trabajadores y la Ley Básica del Empleo, atacando al Gobierno por el retraso de las primeras elecciones sindicales, así como por su política autonómica.

Posteriormente se refirió al fenómeno terrorista de Euskadi, así como al de carácter fascista. «Un terrorismo cada vez más crispado y alejado de los intereses generales de Euskadi y más próximo a la provocación y al aprovechamiento ultraderechista... También hemos visto un envalentonamiento de las bandas fascistas en actos de terrorismo que quedan impunes y que incluso tienen lugar con claros indicios de complicidad de miembros del aparato del Estado, como es el caso de los asesinatos de Hendaya» ${ }^{9}$.

Se manifestó igualmente contrario al PSOE y a la central sindical UGT por no potenciar la unidad de la izquierda. «El intento de protagonizar una política de alternativa, de claras connotaciones socialdemócratas, le ha llevado a repetidas maniobras tácticas para acercarse al poder marginando a los comunistas e intentando romper a UCD para proponer una alianza con algunos de sus sectores» ${ }^{10}$.

- Antoni Gutiérrez Díaz, Informe del Comité Central. V Congreso del PSUC, volumen I, pág. 4.

7 Ibid.

${ }^{8}$ Ibíd., pág. 6.

' Ibíd., pág. 8.

${ }^{10}$ Ibíd., pág. 8. 


\section{c) La situación en Cataluña}

Resaltó la implantación del Pacto Municipal con el PSC-PSOE y los éxitos derivados del mismo.

Criticó la abstención como consecuencia de la separación existente entre los partidos políticos y las masas. Criticó igualmente la actuación del partido en temas tales como el feminismo y la juventud, así como su actuación entre los intelectuales. Se refirió posteriormente a la situación sindical en Cataluña, resaltando la importancia del sindicato CC. OO. en el contexto.

Realizó un análisis de la situación económica en Cataluña, paro, inflación, perspectivas, etc.

Analizó las elecciones del 20 de marzo, resaltando la pérdida de votos de la izquierda en favor de los partidos catalanistas.

\section{d) El partido}

Se refirió a la insuficiente relación existente entre el Comité Central y el Comité Ejecutivo del partido, afirmando que sería prioritario potenciar dicha relación "1. Refiriéndose a la conexión entre el grupo parlamentario y el partido indicó: «Nos referimos a la necesidad de intensificar las relaciones de nuestros parlamentarios cor" el conjunto del partido y con la población... y hemos iniciado un cierto trabajo, pero es todavía insuficiente, especialmente en lo que se refiere a nuestros represel, tantes en el Parlamento español, cuya tarea queda alejada de un seguimiento y un $n$ valoración por parte del partido y la población...»12. Manifestó igualmente el relá. tivo fracaso de los medios de comunicación dependientes del partido, especialment" en lo que se refiere a su escasa tirada ${ }^{13}$.

En cuanto a la financiación del partido, indicó cómo el «PSUC no tiene otros in. gresos que los que le provienen de sus militantes, amigos y simpatizantes» ${ }^{14}$ y que hasta ahora había sido suficiente para afrontar los gastos, aunque éstos habían su. frido importantes incrementos, lo que en un futuro podría significar un endeudamiento exterior. De hecho, ya en 1980 la estructura del presupuesto era deficitaria... En este sentido manifestó que era muy preocupante la disminución de las entradas en la Caja Central por cotizaciones, carnets y campañas de ayuda. A este respecto, se refirió a la sensible pérdida de militantes dentro del partido; «dando como punto de referencia los 40.000 carnets entregados por vez primera después del franquismo, la pérdida global sería de unos 14.000 militantes, de los cuales 3.520 corresponden a la ciudad de Barcelona, 3.339 al Baix Llobregat y 2.580 al Vallés Occidental, como cifras de mayor significación absoluta» ${ }^{15}$.

Como consecuencia de estos datos, indicó que debían potenciarse las agrupaciones territoriales mediante una concepción menos elitista.

Posteriormente se definió como partido de clases, así como partido nacional frente al catalanismo conservador de la derecha. Asimismo pidió la puesta en marcha del centralismo democrático dentro del partido.

${ }^{11}$ Es de destacar que el sector Bandera Blanca está ampliamente representado en el grupo parlamentario.

${ }_{12}$ Volumen I del citado Congreso, pág. 26.

${ }_{13}$ Tredau: 6.000 ejemplares. Noues Horizonts: 1.500 ejemplares.

${ }^{14}$ Vol. I del Congreso, pág. 27.

is Ibíd., pág. 29. 
Por último, se refirió a la relación entre el PCE-PSUC, manifestando la voluntad de independencia del PSUC: «Tradicionalmente, las relaciones entre el PCE y el PSUC han sido las de dos partidos comunistas que comparten responsabilidades de dirigir el proceso revolucionario en un mismo Estado, es decir, con una causa fundamentalmente común y orientada por un mismo pensamiento revolucionario. Esto ha hecho que actuemos como un todo único en aquello que hace referencia a la elaboración de las orientaciones políticas a nivel de España y la política internacional, siendo organizativamente dos partidos diferentes. Por tanto, respecto a Cataluña, las decisiones de los organismos de dirección del PSUC han de ser soberanos y tienen que contar, a la vez, con la ayuda inestimable que representa la solidaridad del PCE en la defensa de la política del PSUC en aquello que tiene repercusión estatal» ${ }^{16}$.

Los principales puntos de matización y discrepancia con el informe presentado por el secretario general del Comité Central fueron los siguientes:

\section{Pactos del partido}

«Al nivel que sea ha de hacerse bajo las siguientes premisas: primera, transparencia plena e información puntual - no a posteriori- de lo que se está debatiendo y prever lo más posible de las contrapartidas que se habrán de aceptar» (Delegación de Barcelona, A).

«La política de consenso en la que hemos participado no solamente ha servido para elaborar la Constitución, sino que ha sido en su conjunto una ofensiva de la burguesía en el plano social, económico y político... El partido hubiese tenido que prever los resultados de esta política, así como el papel desmovilizador de los Pactos de la Moncloa y su incumplimiento. Era muy claro que la derecha no cumpliría muchos de los aspectos firmados en el Pacto de la Moncloa, y que nosotros no fuimos capaces de denunciarlo con energía ni de crear un amplio movimiento contra este incumplimiento» (Delegación del Maresmo, Vallés Oriental, Osona y Ripollés).

\section{Alianza con los socialistas}

«Nosotros no podemos caer en el peligro de ir a remolque de una política de derechas si respaldamos un pacto UCD-PSOE, que representaría ni más ni menos que la presencia de una parte de un sector del movimiento obrero y sindical en el Gobierno sin estar fundamentado en un programa de Gobierno que plantease alternativas y soluciones a los principales problemas. Por tanto, nosotros debemos fundamentalmente nuestra táctica y estrategia en función de una propuesta de la unidad de la izquierda que no excluye alianzas tácticas en momentos determinados por cuestiones concretas si estas alianzas favorecen a los intereses generales de la clase trabajadora y de las clases populares. Esta, creemos, ha de ser nuestra política, la política de los comunistas a nivel de Cataluña y de España» (Delegación de Barcelona, B).

«E1 informe nos presenta la posibilidad de un Gobierno UCD-PSOE apayado por los comunistas, sin definirse al respecto. Opinamos que no debemos apoyar un Gobierno de estas características sin un programa previo discutido, negociado y con mecanismos de control. Debemos trabajar en la dirección de crear una nueva mayoría sustentada en la unidad de la izquierda en base a un programa a corto y medio plazo.»

${ }^{16}$ Ibid., pág. 30. 


\section{Relaciones con el PCE}

«Independencia del partido en las relaciones internacionales. $\mathrm{Ha}$ habido unas propuestas que han planteado unos camaradas; nosotros hemos decidido en el resumen final la profundización en lo elaborado hasta ahora entre el Partido Comunista de España y el Partit Socialista Unificat de Catalunya sin romper nada de lo acordado, pero profundizando en ver cómo ha de participar más el PSUC en toda la elaboración y participación en la cuestión política internacional» (Delegación de Barcelona, B).

«Insistimos que para nosotros resulta indeclinable la plena capacidad y libertad para decidir nuestras propias opiniones, cualquiera que sea la materia y sin que ello signifique menoscabar la relación de colaboración estrecha que indiscutiblemente debemos mantener, en primer lugar con el PCE y después con el resto de los partidos comunistas del mundo» (Delegación del Baix Llobregat).

\section{Absentismo}

Profundizar autocríticamente en cuestiones como nuestra parte de responsabilidad en el desencanto y el abstencionismo que se ha producido durante este período. Se ha considerado en la Delegación que no hay un elemento autocrítico suficiente en la responsabilidad que tiene el partido de una manera concreta en el desencanto, en el abstencionismo que se ha producido, en la medida que muchas veces se han confundido las posiciones de las diversas fuerzas políticas de derecha y de izquierda al no haber unos planteamientos claros y concretos, una imagen propia del partido y de la izquierda en general ante los problemas, y que muchas veces se han identificado demasiado la derecha y la izquierda, como si todos fuésemos iguales, es decir, con los comentarios de que partidos políticos son la clase política, etc. (Delegación de Barcelona, B).

\section{Terrorismo}

«Los comunistas deberíamos tener mucho cuidado en no vernos mezclados en la aprobación de leyes 'antiterroristas' o de 'seguridad ciudadana' que dan amplio margen a la policía y de las cuales no podemos garantizar una aplicación escrupulosa y democrática por unos aparatos de Estado que siguen en gran parte con las costumbres propias del régimen franquista» (Delegación del Vallés Occidental).

\section{Eurocomunismo}

Fue el punto más debatido en el Congreso, pronunciándose la mayoría de los delegados presentes. Como exponente de ello reproducimos las intervenciones de la Delegación B de Barcelona y de la del Vallés Occidental, una a favor y otra en contra de la supresión del término.

«En relación al eurocomunismo - como cuestión final-, hemos decidido que es necesario la profundización de toda esta temática y no hacer una división artificial del partido en este Congreso. Me explicaré: ha habido camaradas que han planteado, efectivamente, la supresión del término eurocomunismo y no han votado, y no sabemos si los planteamientos que tenían estos camaradas hubiesen tenido mayoría 
o minoría; no lo planteamos, pero en estos momentos no se trataba de abrir el gran debate sobre la palabra, sino de profundizar sobre el contenido que expresa. Se ha de profundizar en este informe y en las tesis en lo que es la política de los comunistas en Cataluña, la política del PSUC, que esto es lo fundamental, que nosotros no podemos entrar ahora, en estos momentos, en una polémica falseada ya inicialmente. No me refiero a cuándo se inventó el término eurocomunista, sino lo que ahora, en estos momentos, representaría de cara al exterior, de cara a las masas; se diría que aquí se ha liquidado una política de revolución de la mayoría, de socialismo en libertad, por una política, no sé: como 'afgana', 'afro'..., todo lo que ha nombrado la prensa durante estos días. Por tanto, eurocomunismo, como nosotros lo vemos en lo que hace al informe, como un elemento descriptivo, pero que es el contenido del informe, un contenido de clase, un contenido de izquierdas, un contenido comunista el que marca y ha de marcar la línea de los comunistas a partir de este Congreso" (Delegación de Barcelona, B).

«Primero estamos en desacuerdo con que se emplee esta expresión para calificar nuestro proyecto de revolución de la mayoría y de la vía democrática hacia el socialismo, que tuvo en el marco del IV Congreso su mayor elaboración, pero cuyos orígenes se remontan al VI Congreso del PCE, a partir del cual se profundizó en la política de reconciliación nacional y, posteriormente, de pacto por la libertad, así como la formulación de la democracia social y política formulada en los últimos años.

»Por consiguiente, no compartimos la idea de que eurocomunismo sea igual a vía democrática bacia el socialismo y revolución de la mayoria. Lo mismo decimos de la política por la paz y la desaparición de los bloques, que no es de ahora.

»Consideramos que este Congreso no debe oficializar el término eurocomunismo, pues ello significaría introducir, tal y como sucedió en el IV Congreso con el leninismo, un factor de división en el seno del partido, pues no hay que ignorar que hay una amplia militancia que no se identifica con este objetivo ni lo desea para caracterizar nuestro partido.

»Consideramos que el PSUC es un partido comunista, y punto. Y que, precisamente por ser tal, ha de estar abierto a la sociedad, sin necesidad de adjetivos. No obstante, consideramos que cada miembro del partido debe sentirse con plena libertad a nivel individual si es que quiere reclamarse de este u otro calificativo. Pero de ahí a que esto se eleve a rango de línea y de concepción, suponiendo una obligación para todo el partido, consideramos que no es positivo" (Delegación del Vallés Occidental).

Igualmente se hicieron otro tipo de matizaciones sobre temas menos conflictivos cara al desarrollo del Congreso, tales como la incorporación española a la Comunidad Económica Europea, el ingreso de España en la OTAN y sobre la actitud de la Iglesia ante el momento político español.

Posteriormente fue presentado el resumen de la discusión sobre el informe del Comité Central saliente por Antoni Gutiérrez Díaz, sometiendo posteriormente a votación el informe y resumen, alcanzándose los siguientes resultados: 419 a favor, 78 en contra y 282 abstenciones. 